\title{
AN AUTOPSY BASED STUDY OF PATTERN OF INJURIES IN PERSONS WITH HISTORY OF FALL FROM TRAIN AND JUMPING IN FRONT OF RUNNING TRAIN
}

\author{
K. Valsala1, Sreelekshmi J², Sreedevi C. S3 \\ ${ }^{1}$ Assistant Professor, Department of Forensic Medicine, Government Medical College, Trivandrum. \\ 2Junior Resident, Department of Forensic Medicine, Government T. D. Medical College, Alappuzha. \\ ${ }^{3}$ Professor and HOD, Department of Forensic Medicine, Government T. D. Medical College, Alappuzha.
}

\section{ABSTRACT}

\section{BACKGROUND}

Large scale disruption of different body parts is seen in fatal railway incidents whether accidental or suicidal. Careful examination of body parts is necessary to find the relative position of victim and train during the occurrence of incident. Extensive mutilation of the body makes identification difficult and the relatives often refuse to believe that their family member committed suicide. An attempt is made to study the pattern of injuries that occur during accidental fall from train and suicidal jumping in front of the train, so that it may help a forensic pathologist to suggest a possible manner of death when sufficient history is not available.

\section{MATERIALS AND METHODS}

A descriptive study of all railway track deaths brought for medicolegal autopsy at Thiruvananthapuram Medical College, Kerala, from $1^{\text {st }}$ March 2010 to $28^{\text {th }}$ February 2011 were analysed. A total of 104 cases of railway track deaths were studied excluding cases with advanced decomposition. Data regarding nature of incidents were collected from the Kerala Police Form 102 (KPF 102), investigating officers and relatives. Clinical case records were studied in treated cases. A meticulous external and internal examination was made and the details regarding nature, dimensions and location of injury was entered in a proforma. The data were entered in MS Excel and statistical analysis was done.

\section{RESULTS}

Out of the 104 cases of railway occurrence, six cases (5.8\%) were those with history of fall from running train and 20 (19.2\%) cases were with history of jumping in front of train. External injury was present in all the cases. In all the cases, head showed lacerated wounds and the upper limbs showed abrasion. All the cases showed soft tissue injuries on the head and face. Fracture of the skull bone was seen in $66.6 \%$ of cases. Head alone was injured in $83.3 \%$ of cases and head and neck were involved in 1 case. Soft tissue injury was present in three cases (50\%). Injury to chest was present in $66.6 \%$ of cases. In $50 \%$ of cases, the liver was found lacerated either alone (16.6\%) or in combination with other viscera (33.3\%). Chest alone and abdomen alone were injured in 1 case (16.6\%) each. Chest along with abdomen was injured in 3 cases (50\%). In two cases, there was transection of the body at the level of abdomen, in one of which the chest structure also was injured. External injury of pelvic region was present in $50 \%$ of cases, while fracture occurred in only one case. The upper limb showed fracture in two cases (33.3\%); in one at single site (left elbow) and in the other at multiple sites. The lower limb showed multiple fractures (16.6\%) in one case. In the case with fracture of the left elbow joint there was an abrasion on the back of left elbow, the upper four ribs on left side were fractured on the back aspect and head showed contusion with lacerated wound on right side. In Group II abrasions and lacerated wounds were the major types of injuries seen in this group showing a frequency of $90 \%$ each. In all the cases head showed lacerated wound, of which $35 \%$ were crushed lacerated wounds. Face alone showed injury in $5(25 \%)$ cases. In 10 cases (50\%) there was extrusion of brain, in which two cases (10\%) showed decapitation and 3 cases (15\%) cervical spine fracture. In two cases (10\%), the spinal column was injured in between the VII cervical and I thoracic vertebrae. Two cases $(10 \%)$ showed spinal cord contusion and in one case (5\%) the spinal cord was lacerated. In $60 \%$ of cases, abdomen was found injured. Three cases (15\%) showed transection of the trunk; one each at the level of chest, abdomen and pelvis. In 14 cases, chest was injured. The most frequently affected chest structure was rib (70\%) and lung (60\%).

\section{CONCLUSION}

High frequency of head injury was seen in cases with histories of fall from running train and jumping in front of train. Transection injuries were common in cases with history of jumping in front of train (15\%). Extensive injuries were seen in cases with history of jumping in front of train, because the chance of getting overrun by the train was higher in this case and head and limbs were the most vulnerable regions to injury.

\section{KEYWORDS}

Pattern of Rail Track Injuries, Fall from Running Train, Jumping in Front of Train, Railway Accidents, Railway Suicides.

HOW TO CITE THIS ARTICLE: Valsala K, Sreelekshmi J, Sreedevi CS. An autopsy based study of pattern of injuries in persons with history of fall from train and jumping in front of running train. J. Evolution Med. Dent. Sci. 2017;6(73):5186-5189, DOI: $10.14260 /$ Jemds/2017/1127 
Financial or Other, Competing Interest: None.

Submission 12-06-2017, Peer Review 22-07-2017,

Acceptance 28-07-2017, Published 11-09-2017.

Corresponding Author:

Sreelekshmi J,

Junior Resident,

Department of Forensic Medicine,

Government T. D. Medical College, Alappuzha.

E-mail: jsreelekshmij@gmail.com

DOI: $10.14260 /$ jemds $/ 2017 / 1127$

\section{(c) $(1) \ominus$}

\section{BACKGROUND}

Correlations between density of rail network, number of passengers and number of suicides by train have been found to be proportional. ${ }^{1}$ Large scale disruption of different body parts are seen in fatal railway incidents whether accidental or suicidal. Careful examination of body parts is necessary to find the relative position of victim and train during the occurrence of incident. The nature of lesion may suggest the pathologist about the consciousness of the victim whether an attempt is made to avoid the hit by the train. Extensive mutilation of the body makes identification difficult and the relatives often refuse to believe that their family member committed suicide. Suicide by train seriously affects not only survivors, but also train drivers and bystanders. ${ }^{2}$ An attempt is made to study the pattern of injuries that occur during accidental fall from train and suicidal jumping in front of the train, so that it may help a forensic pathologist to suggest a possible manner of death when sufficient history is not available.

\section{Aims and Objectives}

1. To study the pattern of injuries among persons with history of fall and jumping in front of running train.

2. To compare the pattern of injuries among persons with history of fall and jumping in front of running train.

\section{MATERIALS AND METHODS}

A descriptive study of all railway track deaths brought for medicolegal autopsy at Thiruvananthapuram Medical College, Kerala, from $1^{\text {st }}$ March 2010 to 28 $8^{\text {th }}$ February 2011 were analysed. A total of 104 cases of railway track deaths were studied excluding cases with advanced decomposition. The persons with history of fall from running train was assigned as Group I and persons with history of jumping in front of running train was assigned as Group II. Data regarding nature of incidents were collected from the Kerala Police Form 102 (KPF 102), investigating officers and relatives. Clinical case records were studied in treated cases. A meticulous external and internal examination was made and the details regarding nature, dimensions and location of injury was entered in a proforma. The data were entered in MS Excel and statistical analysis was done.

\section{RESULTS}

\section{Group I. Cases with History of Fall from Running Train}

Out of the 104 cases studied, six cases $(5.8 \%)$ were those with history of fall from running train. External injury was present in all the cases. The most common types of external injuries were lacerated wound and abrasion. In all the cases, head showed lacerated wounds and the upper limbs showed abrasion (Table 1). All the cases showed soft tissue injuries on the head and face. $66.6 \%$ of cases showed fracture of the skull bone. None of the cases showed facial bone fracture. In only one case, the neck showed soft tissue injury (abrasion).
In yet another case, there was cervical spine fracture. In the present study, it is observed that in cases of fall from running train, head injury is present in all cases (Table 2). Head alone was injured in $83.3 \%$ of cases and head and neck were involved in 1 case. Soft tissue injury was present in three cases (50\%). Injury to chest was present in $66.6 \%$ of cases.

In $50 \%$ of cases, the liver was found lacerated either alone $(16.6 \%)$ or in combination with other viscera $(33.3 \%)$. Chest alone and abdomen alone were injured in 1 case $(16.6 \%)$ each. Chest along with abdomen injured in 3 cases $(50 \%)$. In two cases, there was transection of the body at the level of abdomen, in one of which the chest structure also was injured. In two cases $33.3 \%$ there was only external injury (abrasion). Injury to chest and abdomen can occur either isolated or in combination with each other. External injury of pelvic region was present in $50 \%$ of cases, while fracture occurred in only one case. In the case with fracture of the pelvic bone according to the investigating officer, the person fell down and run over by the train. The abdomen was transected. There was no external injury to the pelvic region. In this case, there was associated injury to the chest also. While in the other case with transection of abdomen, the person was travelling on the footsteps by holding on the hand rail. In the first case, there was associated amputation of the left humerus and fracture of the left clavicle. In the second case, there was no associated injury. The upper limb showed fracture in two cases (33.3\%); in one at single site (left elbow) and in the other at multiple sites. The lower limb showed multiple fractures $(16.6 \%)$ in one case. In the case with fracture of the left elbow joint there was an abrasion on the back of left elbow, the upper four ribs on left side were fractured on the back aspect and head showed contusion with lacerated wound on right side. In case of fall from running train, transection had occurred in only two cases. In all the cases, the victim need not be run over by the train. Death can occur from injuries due to fall also.

\section{Group II. Jumping in Front of the Train}

Out of 104 cases studied, 20 cases (19.2\%) were brought with history of jumping in front of the train. Abrasions and lacerated wounds were the major types of injuries seen in this group showing a frequency of $90 \%$ each. In all the cases head showed lacerated wound, of which $35 \%$ were crushed lacerated wounds (Table 1). Face alone showed injury in 5 $(25 \%)$ cases. In 10 cases (50\%) there was extrusion of brain, in which two cases $(10 \%)$ showed decapitation and 3 cases (15\%) cervical spine fracture. In two cases $(10 \%)$, the spinal column was injured in between the VII cervical and I thoracic vertebrae. Two cases (10\%) showed spinal cord contusion and in one case (5\%) the spinal cord was lacerated. In $60 \%$ of cases, abdomen was found injured (Table 2). The abdominal viscera most frequently injured was liver. Liver laceration was present in $50 \%$ of the cases. The other abdominal organs frequently affected were spleen (30\%), kidney $(20 \%)$ and intestine and mesentery (20\%). Three cases (15\%) showed transection of the trunk; one each at the level of chest, abdomen and pelvis. In 14 cases, chest was injured. The most frequently affected chest structure was rib (70\%) and lung $(60 \%)$. It is observed that the frequency of traumatic amputation and fracture in the upper limb were 30\% and $50 \%$ respectively and in the lower limb $30 \%$ and $45 \%$ respectively (Figure 1). In cases with history of jumping in front of train, head and limbs were the most vulnerable regions of injury. 


\begin{tabular}{|c|c|c|c|c|c|c|c|c|}
\hline Injury & Groups & Head (n \%) & Neck (n \%) & $\begin{array}{c}\text { Upper Limbs } \\
\text { (n \%) }\end{array}$ & $\begin{array}{l}\text { Chest } \\
\text { (n \%) }\end{array}$ & $\begin{array}{c}\text { Abdomen } \\
\text { (n \%) }\end{array}$ & $\begin{array}{c}\text { Pelvic Region } \\
\text { (n \%) }\end{array}$ & $\begin{array}{c}\text { Lower Limbs } \\
\text { (n \%) }\end{array}$ \\
\hline \multirow{2}{*}{ Abrasion } & Group I & 5 (83.3) & $1(16.67)$ & $6(100)$ & $3(50)$ & $3(50)$ & $3(50)$ & $5(83.3)$ \\
\hline & Group II & $10(50)$ & $6(30)$ & $18(90)$ & $13(65)$ & 0 & 0 & $18(90)$ \\
\hline \multirow{2}{*}{ Contusion } & Group I & $4(66.6)$ & 0 & $1(16.6)$ & $2(33.3)$ & 0 & 0 & 0 \\
\hline & Group II & 0 & 0 & $1(5)$ & $1(5)$ & 0 & 0 & $1(5)$ \\
\hline \multirow{2}{*}{$\begin{array}{c}\text { Abraded } \\
\text { Contusion }\end{array}$} & Group I & 0 & 0 & 0 & 0 & 0 & 0 & $1(16.67)$ \\
\hline & Group II & $2(10)$ & 0 & $4(20)$ & $3(15)$ & $1(5)$ & 0 & $2(10)$ \\
\hline \multirow{2}{*}{$\begin{array}{c}\text { Lacerated } \\
\text { Wound }\end{array}$} & Group I & $6(100)$ & 0 & $2(33.3)$ & 0 & 0 & 0 & $4(66.6)$ \\
\hline & Group II & $20(100)$ & $4(20)$ & $18(90)$ & $6(30)$ & $5(25)$ & $2(10)$ & $17(85)$ \\
\hline
\end{tabular}

\begin{tabular}{|c|c|c|c|c|c|c|}
\hline Group (n= 26) & Head n (\%) & Neck n (\%) & Chest n (\%) & Abdomen n (\%) & Upper Limb n (\%) & Lower Limb n (\%) \\
\hline Group I (n=6) & $6(100)$ & $1(16.6)$ & $4(66.6)$ & $4(66.6)$ & $2(33.3)$ & $1(16.6)$ \\
\hline Group II (n= 20) & $20(100)$ & $7(35)$ & $14(70)$ & $12(60)$ & $11(55)$ & $12(60)$ \\
\hline \multicolumn{7}{|c|}{ Table 2. Distribution of Persons with Injury according to Body Part } \\
affected and in different Railway Injury Groups (Groups I and II) \\
\hline
\end{tabular}

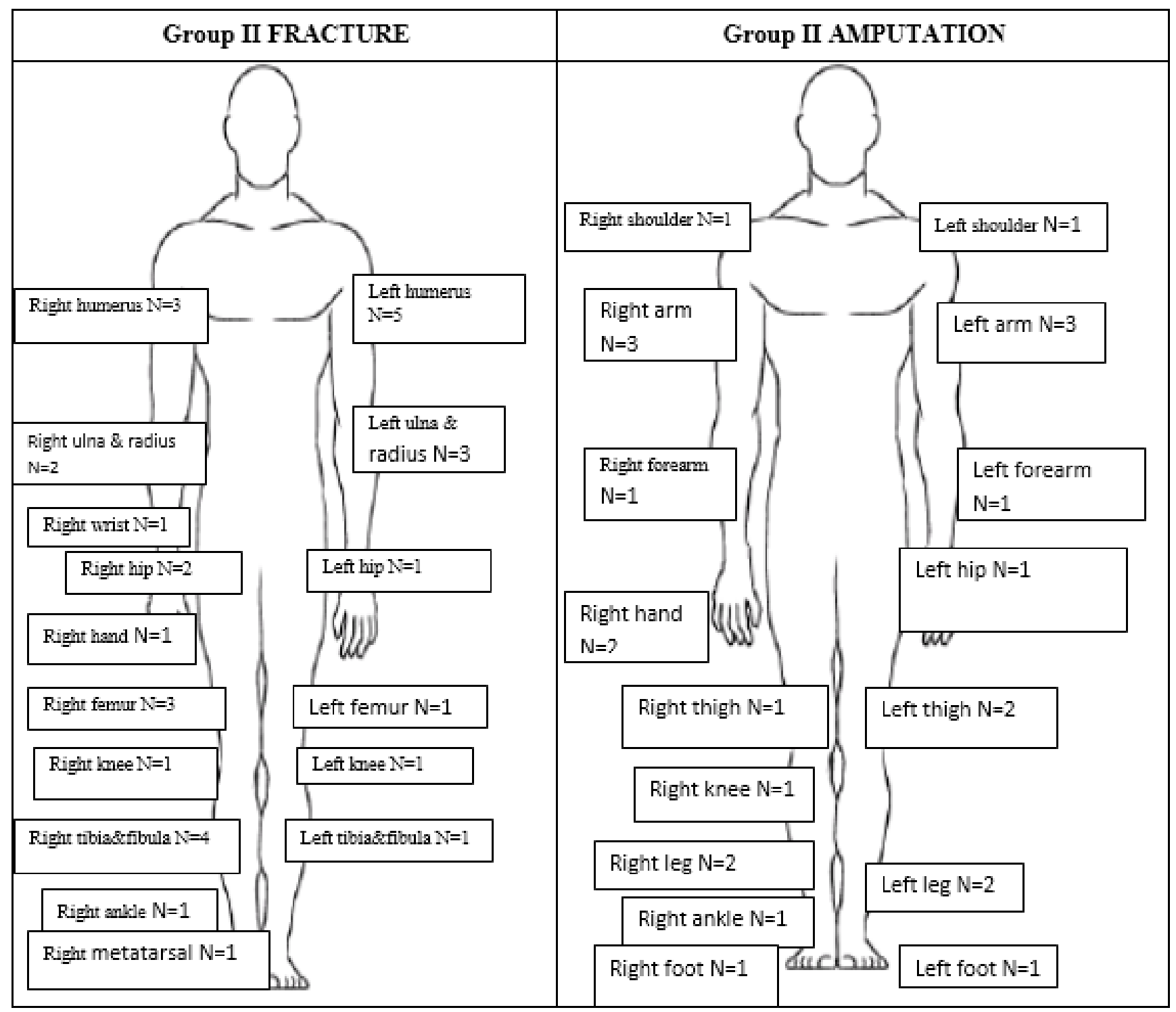

Figure 1. Level of Amputations among Persons Jumping in Front of Train 


\section{DISCUSSION}

\section{Group I. Cases with History of Fall from Running Train}

The Group I is comprised of six cases (5.8\%) with history of falling from running train. In this group the external injuries like abrasions, lacerations were the predominant type. Abrasion and lacerated wounds were present mainly on the upper limbs and head respectively in all the cases. Contusion showed a higher percentage of distribution on the head 83.3\%. This is in agreement with study done by Ammamulla ${ }^{3}$ and Hu YP. ${ }^{4}$ In $66.6 \%$ of cases showed skull fracture either alone or in combination with membrane haemorrhages or brain injury or both. Most of the cases were free of injury to neck. There was no decapitation injury. Amputations of limbs were also less in this group. Transection was seen in two cases $(33.3 \%)$ at the level of abdomen.

Fifty percentage of the cases showed fracture of the vertebral column involving cervical $(16.6 \%)$ and thoracic spines $(33.3 \%)$ as stated by Krishan Vij. ${ }^{5}$ On the chest, rib was the mostly affected structure (66.6\%). In $50 \%$ of cases, abdominal injury was present and the most commonly affected organ was liver. Amputation and fracture of the limbs were less in this group.

\section{Group II- Jumping in Front of Train}

This included 20 cases (19.2\%). Lacerated wounds and abrasions were the major types of injuries. In all the cases there was lacerated wounds on the head, of which $35 \%$ were crushed lacerated wounds. The upper limbs and lower limbs also showed lacerated wounds ( $90 \%$ and $85 \%$ respectively). In $80 \%$ of cases, there was fracture of the skull and $50 \%$ showed extrusion of brain. Two cases (10\%) showed decapitation as discussed by Sheikh MI et al. ${ }^{6}$ Frequency of transection was higher in this group also. Fifteen percent was noted at the abdomen. Chest and pelvic regions showed a frequency of $10 \%$ and $5 \%$ respectively. Traumatic amputation and fracture in the upper limb were 30\% and $50 \%$ respectively in this group and in the lower limb the frequency was $30 \%$ and $45 \%$ respectively as in agreement with Ramesh Nanaji. ${ }^{7}$ In cases with history of jumping in front of train, head and limbs were the most vulnerable regions.

\section{Comparison of Injury Patterns among the Groups}

Comparison was made between the injury pattern in Group I (With history of fall from running train- accidental) and Group II (with history of jumping in front of train- suicidal). In both the groups, all the cases showed injury to head. The limbs were involved more in the group of suicidal jumping in front of train. In Group I, none of the cases showed decapitation injury, while in Group II three cases $(15 \%)$ showed decapitation.

Only one case among Group I victims showed transection of the trunk at the level of abdomen. In Group II three cases (15\%) showed transection, 1 each at the level of chest, abdomen and pelvis. In cases of fall from running train, the body may be slipped under the train due to the centrifugal force in accordance with the Bernoulli's theorem and may get run over. In case of running in front of train, the body will not be thrown out and there is more chances of getting overrun by the train. When the incidence of transection through head region and decapitation were compared in all the six groups. In this study, incidence of transection was higher in cases with history of jumping in front of train when the incidence of transection through the chest, abdomen and pelvic region were compared in all the six groups. In the present study in Group 1, there was transection at the level of abdomen in one case. In Group II, there was transection one each at the level of chest, abdomen and pelvis in three cases. In cases of fall from running train, the body may be slipped under the train due to the centrifugal force in accordance with the Bernoulli's theorem and may get run over.

\section{CONCLUSION}

High frequency of head injury was seen in cases with histories of fall from running train and jumping in front of train. Transection injuries were common in cases with history of jumping in front of train. Extensive injuries were seen in cases with history of jumping in front of train, because the chance of getting overrun by the train was higher in this case and head and limbs were the most vulnerable regions of injury.

\section{ACKNOWLEDGEMENTS}

We extend our sincere gratitude to Dr. P. Rema (Professor and Head of The Department of Forensic Medicine, Trivandrum) and all other teachers and faculties of Trivandrum Medical College for the guidance, valuable and inspiring sense of communications and interactions in this study.

\section{REFERENCES}

[1] Krysinska K, De Leo D. Suicide on railway networks: epidemiology, risk factors and prevention. Aust N Z J Psych 2008;42(9):763-71.

[2] Satish NT, Anitha, Chandra G, et al. Delivery and death on railway track -a case report. J Punjab Acad Forensic Med Toxicol 2013;13(1):33-7.

[3] Ammamullah S. Railway death in Jammu \& Kashmir. Medical News Medicine \& Law 1983: 101-5.

[4] Hu YP, Cao Y, Ma KJ. Analysis of the death cases in the urban rail traffic accident in Shanghai. Fa Yi Xue Za Zhi 2009;25(3):198-9.

[5] Krishan VIJ. Textbook of forensic medicine and toxicology: principles and practice. India: Elsevier 2008:370-2.

[6] Sheikh MI, Shah JV, Patel R. Study of deaths due to railway accident. Journal of Indian Academy of Forensic Medicine 2008;30(3):122-7.

[7] Wasnik, Nanaji R. Analysis of railway fatalities in central India. J Indian Acad Forensic Med 2010:32(4). 